\title{
A Convenção da Criança e os Limites na Responsabilização de Crianças e Adolescentes no Brasil: Rupturas e Permanências
}

The Child Convention and the Limits on the Liability of Children and Adolescents in Brazil: Ruptures and Permanences

\section{Luanna Tomaz de Souza'}

1 Universidade Federal do Pará, Belém, Pará, Brasil. E-mail: luannatomaz@gmail.com. ORCID: https://orcid.org/0000-0002-8385-8859.

\section{Fernando da Silva Albuquerque ${ }^{2}$}

2 Universidade Federal do Pará, Belém, Pará, Brasil. E-mail: fsalbuquerque@ymail.com. ORCID: https://orcid.org/0000-0001-7074-6949.

\section{Josilene Barbosa Aboim³}

3 Universidade Federal do Pará, Belém, Pará, Brasil. E-mail: josilene.aboim@gmail.com. ORCID: https://orcid.org/0000-0002-8509-0273.

Artigo recebido em 26/12/2018 e aceito em 23/03/2019.

\section{(cc) $\mathrm{Br}$}

This work is licensed under a Creative Commons Attribution 4.0 International License. 


\section{Resumo}

A presente pesquisa buscará verificar a contribuição da Convenção sobre os Direitos da Criança (1989) para estabelecer limites ao poder estatal na responsabilização de crianças e adolescentes em conflito com a lei no Brasil. Será utilizado o método dialético com suporte em bases bibliográficas e documentais para analisar as rupturas e permanências na apuração de atos infracionais existentes em período anterior e posterior à vigência da Convenção.

Palavras-chave: Convenção da Criança; Ato infracional; Poder punitivo.

\section{Abstract}

This research will seek to verify the contribution of the Convention on the Rights of the Child (1989) to establish limits to state power in the responsabilization of children and adolescents in conflict with the law in Brazil. The dialectical method will be used with bibliographical and documentary bases to analyze the ruptures and stays in the investigation of infractions existing before and after the validity of the Convention.

Keywords: Children's Convention; Infraction act; Punitive power. 
Introdução

No ano de 2019, completa-se 30 anos da Convenção sobre os Direitos da Criança, adotada em Assembleia Geral das Nações Unidas, em 20 de novembro de 1989, e promulgada pelo Decreto no 99.710, de 21 de novembro de 1990, no Brasil. Este importante documento, por meio de seus 54 artigos, contribuiu significativamente para o reconhecimento dos direitos de crianças e adolescentes em âmbito mundial.

A Convenção é um dos mais amplos tratados internacionais de direitos humanos, ratificada por 193 países, fazendo com que vários deles incorporassem na sua legislação nacional estatutos sobre o tema e efetuassem reformas jurídicas baseadas nos dispositivos da Convenção. Trata-se do instrumento de direitos humanos mais ratificado em escala mundial, sendo que a grande maioria das ratificações ocorreu nos primeiros 10 anos após sua aprovação (ROSEMBERG; MARIANO, 2010).

Um dos aspectos que devem ser ressaltados é sua preocupação em sustar algumas das violações perpetradas pelos Estados no âmbito punitivo criando diferenças quanto aos mecanismos de sistema de justiça criminal, mas impondo direitos e garantias. Nos termos da Convenção, por exemplo, a intervenção dirigida aos adolescentes infratores deve promover e estimular seus sentidos de dignidade e de valor, e fortalecer o respeito destes pelos direitos humanos e pelas liberdades fundamentais de terceiros (art. 40).

A presente pesquisa buscará verificar a relevância dos limites estabelecidos pela Convenção ao poder estatal, na responsabilização de crianças e adolescentes em conflito com a lei e seu impacto no Brasil. Percebe-se, no país, que, à revelia do que determinam a Convenção e o Estatuto da Criança e do Adolescente- ECA (Lei no 8.069, de 13 de julho de 1990), a socioeducação tornou-se uma ferramenta à serviço da punitividade estatal, que, além de atribuir-lhes a qualidade de sujeitos perigosos, com a conivência das normas jurídicas brasileiras, retirou-lhes direitos (ABOIM, 2018).

De acordo com o Levantamento anual do Sistema Nacional de Atendimento Socioeducativo -SINASE (BRASIL, 2016), em 2016, tínhamos um total de 26.450 atendidos, sendo 18.567 em medida de internação (70\%), 2.178 em regime de semiliberdade (8\%) e 5.184 em internação provisória (20\%). Há, ainda, outros 334 adolescentes/jovens em atendimento inicial e 187 em internação sanção. O Conselho 
Nacional de Justiça - CNJ, por meio do Cadastro Nacional de Adolescentes em Conflito com a Lei, aponta o número de 189 mil adolescentes cumprindo medidas socioeducativas no país, a maioria está em medidas em meio aberto, mas com crescimento exponencial das medidas em meio fechado ano a ano ${ }^{1}$.

Para a análise aqui realizada, a partir do método dialético, serão consideradas as dinâmicas de apuração de atos infracionais existentes no sistema de justiça brasileiro em período anterior e posterior à vigência da Convenção, destacando suas rupturas e permanências. Com suporte em bases bibliográficas e documentais, busca-se compreender as tensões na aplicação das medidas socioeducativas no país.

\section{A Convenção dos Direitos da Criança e a prática infracional}

A noção de criança enquanto sujeito de direitos surge muito contemporaneamente no cenário jurídico internacional. Em 26 de setembro de 1924, temos a primeira Declaração dos Direitos da Criança, que teve como grande avanço reconhecer que a responsabilidade pela criança é coletiva e internacional. Não teve, entretanto, grande impacto sobre os Estados, pois se afirmava como uma declaração de obrigações dos homens e mulheres sem força coercitiva.

Em 20 de novembro de 1959, surge uma segunda declaração perfilhando a necessidade de proteção e cuidados específicos à infância. Este documento, mesmo sem força coercitiva, criou forte impacto internacional, sendo convocadas, a partir dele, diversas reuniões internacionais. Segundo a Declaração, seu objetivo é:

(...) que a criança tenha uma infância feliz e possa gozar, em seu próprio benefício e no da sociedade, os direitos e as liberdades aqui enunciados e apela a que os pais, os homens e as mulheres em sua qualidade de indivíduos, e as organizações voluntárias, as autoridades locais e os Governos nacionais reconheçam estes direitos e se empenhem pela sua observância mediante medidas legislativas e de outra natureza, progressivamente instituídas (UNICEF, 1959).

A Declaração teria consolidado o entendimento de que as crianças e os adolescentes são sujeitos de direito, não meramente objetos destes (ANDRADE, 2010:

1 G1. "Em 1 ano, dobra no de menores cumprindo medidas no país, diz CNJ". Disponível em: <http://g1.globo.com/politica/noticia/2016/11/em-1-ano-dobra-n-de-menores-cumprindo-medidas-nopais-diz-cnj.html>. Acesso em: 22 nov. 2018. 
80). A partir dela, em âmbito internacional, passou a se entender que não somente a criança "pobre e delinquente" seria atendida na sua plenitude, mas, conforme o seu princípio 1ㅇ:

Todas as crianças, absolutamente sem qualquer exceção, (...), sem distinção ou discriminação por motivo de raça, cor, sexo, língua, religião, opinião política ou de outra natureza, origem nacional ou social, riqueza, nascimento ou qualquer outra condição (...) (UNICEF, 1959).

Em 1989, a Convenção sobre os Direitos da Criança ${ }^{2}$, reúne os avanços desses documentos e reafirma a necessidade de proteção da infância, erigindo, ao mesmo tempo, a criança como um sujeito de diversos direitos. A partir da Convenção, as crianças passam a ser vistas como titulares de direitos universalmente reconhecidos que devem ser garantidos tanto pelo Estado, como pela família ou, ainda, pela sociedade como um todo (MACIEL, 2010).

Importante destacar que ela é o primeiro documento internacional a utilizar um critério para definição de criança. Em seu art. $1^{\circ}$, configura a criança como todo ser humano com idade inferior a 18 anos, exceto quando, pela lei do país, a maioridade seja estabelecida antes. Isso é fundamental diante da indeterminação até então vigente. Ressalta-se que, no Brasil, o ECA define criança como todo ser humano até os 12 incompletos e adolescente de 12 aos 18 incompletos.

Em realidade, a compreensão da infância como uma fase diferenciada no desenvolvimento do ser humano é recente e não pode ser entendida dentro de uma mera abstração, mas como reflexo de um conjunto de compreensões sobre família, maternidade, direitos, adolescência, aspectos socioculturais e também jurídicos. Desde o século XII, a sociedade desenvolve modelos para infância, alijando, contudo, determinadas crianças de vivê-los, principalmente as mais pobres (ARIÉS, 1978).

Outro aspecto a ser destacado é que a Convenção erige princípios como o do superior interesse da criança e o da prioridade, que inclusive já estavam consagrados na 2ªeclaração de $1959^{3}$, mas ganham maior relevo no bojo dos mais de 50 artigos que contemplam diversos direitos. Isso causou um profundo impacto. A Convenção também

\footnotetext{
${ }^{2}$ O Decreto ${ }^{\circ}$ 99.710, de 21 de novembro de 1990 promulgou, no país, a Convenção sobre os Direitos da Criança - Resolução 44/25 da Assembleia Geral, de 20 de novembro de 1989.

${ }^{3}$ Ambos estão consagrados no art. 227 da Constituição. 0 primeiro estabelece que todas as ações relativas às crianças devem considerar, especialmente, o "interesse maior da criança" e o segundo estabelece que as ações voltadas à proteção da infância têm prioridade sobre toda e qualquer ação.
} 
criou mecanismos coercitivos, como o Comitê sobre os Direitos da Criança que monitora o cumprimento da Convenção.

No âmbito punitivo, a Convenção deve ser lida em conjunto com diversos documentos que, em alguns, são aplicados igualmente aos adultos: as Regras Mínimas das Nações Unidas para Administração da Justiça Juvenil - Regras de Beijing $(1985)^{4}$, as Diretrizes das Nações Unidas para Prevenção da Delinquência Juvenil - Diretrizes de Riad $(1990)^{5}$,as Regras Mínimas das Nações Unidas para Proteção dos Jovens Privados de Liberdade - as Regras de Havana (1990), ${ }^{6}$ e as Regras Mínimas das Nações Unidas para Medidas Não Privativas de Liberdade - Regras de Tóquio (1990) ${ }^{7}$, também de 1990. Estes documentos são importantes por traçar limites ao que, em regra, ficava sob tutela somente dos Estados.

A Convenção, no bojo dessas preocupações de impor regras à atuação do Estado na responsabilização das crianças e dos adolescentes, estabelece diretrizes importantes como a vedação à tortura, penas cruéis e degradantes, bem como prisões arbitrárias. Além disso, estabelece o direito de defesa e de contato com a família e a separação dos adultos no cumprimento das punições:

\section{Artigo 37}

Os Estados Partes zelarão para que:

a) nenhuma criança seja submetida a tortura nem a outros tratamentos ou penas cruéis, desumanos ou degradantes. Não será imposta a pena de morte nem a prisão perpétua sem possibilidade de livramento por delitos cometidos por menores de dezoito anos de idade;

b) nenhuma criança seja privada de sua liberdade de forma ilegal ou arbitrária. A detenção, a reclusão ou a prisão de uma criança será efetuada em conformidade com a lei e apenas como último recurso, e durante o mais breve período de tempo que for apropriado;

c) toda criança privada da liberdade seja tratada com a humanidade e o respeito que merece a dignidade inerente à pessoa humana, e levando-se em consideração as necessidades de uma pessoa de sua idade. Em especial, toda criança privada de sua liberdade ficará separada dos adultos, a não ser que tal fato seja considerado contrário aos melhores interesses da criança, e

\footnotetext{
${ }^{4}$ Elas estendem aos menores de idade garantias processuais tradicionalmente asseguradas aos maiores de idade. Este texto internacional prega também o desenvolvimento da especialização e da profissionalização da "justiça de menores", assim como o recurso preferencial a procedimentos extrajudiciais e a medidas educativas diversas da privação de liberdade.

${ }^{5}$ Diretrizes para a prevenção dos crimes cometidos por jovens. Este documento que passou a nortear a formulação e a execução de programas e políticas nessa seara, com ênfase nas atividades de assistência e de estímulo à participação da comunidade.

${ }^{6}$ Definem a privação de liberdade de forma ampla, estendendo a proteção a toda forma de internação em estabelecimento público ou privado do qual o jovem não possa sair por sua livre e espontânea vontade.

${ }^{7}$ Disciplinam sobre o ato infracional juvenil em todos os estágios do processo, estabelecendo a privação da liberdade como medida excepcional.
} 
terá direito a manter contato com sua família por meio de correspondência ou de visitas, salvo em circunstâncias excepcionais;

d) toda criança privada de sua liberdade tenha direito a rápido acesso a assistência jurídica e a qualquer outra assistência adequada, bem como direito a impugnar a legalidade da privação de sua liberdade perante um tribunal ou outra autoridade competente, independente e imparcial e a uma rápida decisão a respeito de tal ação (BRASIL, 1990a).

De outro lado, a Convenção adverte sobre a importância da aplicação de todo um manancial principiológico também às crianças, tais como o princípio da legalidade, da não retroatividade, da presunção de inocência, do direito à informação, da ampla defesa e do contraditório, da privacidade e do devido processo legal.

Artigo 40

1. Os Estados Partes reconhecem o direito de toda criança a quem se alegue ter infringido as leis penais ou a quem se acuse ou declare culpada de ter infringido as leis penais de ser tratada de modo a promover e estimular seu sentido de dignidade e de valor e a fortalecer o respeito da criança pelos direitos humanos e pelas liberdades fundamentais de terceiros, levando em consideração a idade da criança e a importância de se estimular sua reintegração e seu desempenho construtivo na sociedade.

2. Nesse sentido, e de acordo com as disposições pertinentes dos instrumentos internacionais, os Estados Partes assegurarão, em particular:

a) que não se alegue que nenhuma criança tenha infringido as leis penais, nem se acuse ou declare culpada nenhuma criança de ter infringido essas leis, por atos ou omissões que não eram proibidos pela legislação nacional ou pelo direito internacional no momento em que foram cometidos;

b) que toda criança de quem se alegue ter infringido as leis penais ou a quem se acuse de ter infringido essas leis goze, pelo menos, das seguintes garantias:

I) ser considerada inocente enquanto não for comprovada sua culpabilidade conforme a lei;

II) ser informada sem demora e diretamente ou, quando for o caso, por intermédio de seus pais ou de seus representantes legais, das acusações que pesam contra ela, e dispor de assistência jurídica ou outro tipo de assistência apropriada para a preparação e apresentação de sua defesa;

III) ter a causa decidida sem demora por autoridade ou órgão judicial competente, independente e imparcial, em audiência justa conforme a lei, com assistência jurídica ou outra assistência e, a não ser que seja considerado contrário aos melhores interesses da criança, levando em consideração especialmente sua idade ou situação e a de seus pais ou representantes legais;

IV) não ser obrigada a testemunhar ou a se declarar culpada, e poder interrogar ou fazer com que sejam interrogadas as testemunhas de acusação bem como poder obter a participação e o interrogatório de testemunhas em sua defesa, em igualdade de condições;

V) se for decidido que infringiu as leis penais, ter essa decisão e qualquer medida imposta em decorrência da mesma submetidas a revisão por autoridade ou órgão judicial superior competente, independente e imparcial, de acordo com a lei;

Rev. Direito Práx., Rio de Janeiro, Vol. 10, N. 02, 2019, p. 1356-1382.

Luanna Tomaz de Souza, Fernando da Silva Albuquerque e Josilene

Barbosa Aboim

DOI: $10.1590 / 2179-8966 / 2019 / 39120 \mid$ ISSN: $2179-8966$ 
VI) contar com a assistência gratuita de um intérprete caso a criança não compreenda ou fale o idioma utilizado;

VII) ter plenamente respeitada sua vida privada durante todas as fases do processo.

3. Os Estados Partes buscarão promover o estabelecimento de leis, procedimentos, autoridades e instituições específicas para as crianças de quem se alegue ter infringido as leis penais ou que sejam acusadas ou declaradas culpadas de tê-las infringido, e em particular:

a) o estabelecimento de uma idade mínima antes da qual se presumirá que a criança não tem capacidade para infringir as leis penais; (BRASIL, 1990a).

Em âmbito nacional, ECA trouxe uma série de ferramentas que se relacionam com o documento internacional. Em seus artigos 110 e 111, assegura aos infratores o devido processo legal, a igualdade processual, defesa técnica por advogado, assistência judiciária gratuita e integral aos necessitados, o direito de ser ouvido pessoalmente pela autoridade competente e o direito de solicitar a presença de seus pais ou responsável em qualquer fase do procedimento, o que demonstra uma correspondência com o viés axiológico da Convenção.

Outros dispositivos importantes são a comunicação imediata à autoridade judiciária competente da apreensão, informando o indivíduo sobre seus direitos, determinando que se examine desde logo e sob pena de responsabilidade a possibilidade de liberação imediata; a internação provisória com o prazo máximo de 45 dias; e a manutenção da apreensão somente se imperiosa necessidade ${ }^{8}$.

A Convenção também não descuidou da importância de se prever medidas não privativas de liberdade para adolescentes acompanhando dinâmicas internacionais inclusive para adultos:

Art. 40.

(...)

3.

\footnotetext{
8“Art. 106. Nenhum adolescente será privado de sua liberdade senão em flagrante de ato infracional ou por ordem escrita e fundamentada da autoridade judiciária competente.

Parágrafo único. $O$ adolescente tem direito à identificação dos responsáveis pela sua apreensão, devendo ser informado acerca de seus direitos.

Art. 107. A apreensão de qualquer adolescente e o local onde se encontra recolhido serão incontinenti comunicados à autoridade judiciária competente e à família do apreendido ou à pessoa por ele indicada.

Parágrafo único. Examinar-se-á, desde logo e sob pena de responsabilidade, a possibilidade de liberação imediata.

Art. 108. A internação, antes da sentença, pode ser determinada pelo prazo máximo de quarenta e cinco dias.

Parágrafo único. A decisão deverá ser fundamentada e basear-se em indícios suficientes de autoria e materialidade, demonstrada a necessidade imperiosa da medida" (BRASIL, 1990b).
} 
b) a adoção sempre que conveniente e desejável, de medidas para tratar dessas crianças sem recorrer a procedimentos judiciais, contando que sejam respeitados plenamente os direitos humanos e as garantias legais.

4. Diversas medidas, tais como ordens de guarda, orientação e supervisão, aconselhamento, liberdade vigiada, colocação em lares de adoção, programas de educação e formação profissional, bem como outras alternativas à internação em instituições, deverão estar disponíveis para garantir que as crianças sejam tratadas de modo apropriado ao seu bem-estar e de forma proporcional às circunstâncias e ao tipo do delito (BRASIL, 1990a).

O ECA trouxe, nessa seara, um importante instituto: a remissão ${ }^{9}$, que exclui o processo, acaso ainda não iniciado o procedimento judicial, ou suspende-o ou extingueo, quando já se deu inicio, atendendo às circunstâncias e consequências do fato, ao contexto social, bem como à personalidade do adolescente e sua maior ou menor participação no ato infracional. Há também, no sistema legislativo brasileiro, quatro medidas socioeducativas alternativas à privação de liberdade, a saber: advertência; obrigação de reparar o dano; prestação de serviços à comunidade; e liberdade assistida.

Ademais, estabelece uma necessária avaliação periódica no que diz respeito à verificação quanto aos avanços, e, ainda, as dificuldades enfrentadas na internação, com vistas à melhoria do atendimento no estabelecimento correspondente, com suporte técnico de equipes multidisciplinares.

\section{Artigo 25}

Os Estados Partes reconhecem o direito de uma criança que tenha sido internada em um estabelecimento pelas autoridades competentes para fins de atendimento, proteção ou tratamento de saúde física ou mental a um exame periódico de avaliação do tratamento ao qual está sendo submetida e de todos os demais aspectos relativos à sua internação (BRASIL, 1990a).

De forma correspondente, o artigo 94 do ECA determina que as entidades que desenvolvem programas de internação têm a obrigação, entre outras, de proceder a estudo social e pessoal de cada caso; reavaliar periodicamente cada caso, com intervalo máximo de seis meses, dando ciência dos resultados à autoridade competente; e informar, periodicamente, o adolescente internado sobre sua situação processual.

${ }^{9}$ Art. 126. Antes de iniciado o procedimento judicial para apuração de ato infracional, o representante do Ministério Público poderá conceder a remissão, como forma de exclusão do processo, atendendo às circunstâncias e consequências do fato, ao contexto social, bem como à personalidade do adolescente e sua maior ou menor participação no ato infracional.

Parágrafo único. Iniciado o procedimento, a concessão da remissão pela autoridade judiciária importará na suspensão ou extinção do processo.

Art. 127. A remissão não implica necessariamente o reconhecimento ou comprovação da responsabilidade, nem prevalece para efeito de antecedentes, podendo incluir eventualmente a aplicação de qualquer das medidas previstas em lei, exceto a colocação em regime de semi-liberdade e a internação (BRASIL, 1990b). 
Percebe-se, então, que essas diretrizes compõem um panorama mínimo de racionalidade para a formatação de modelos de intervenção dos Estados, cujo objetivo é, de um lado, consagrar crianças como sujeitos titulares de direitos e, de outro, erigir limitações ao próprio poder dos Estados, no que diz respeito aos seus mecanismos e itinerários de intervenção, inclusive os de viés retributivo.

A aproximação do texto da Convenção a um arsenal semântico muito próprio da dogmática penal - circunstância também presente em outros documentos internacionais direcionados à relação entre juventude e delinquência - embora contribua para a justificação do poder punitivo do Estado, também fornece, no processo histórico de estabelecimento de marcos democráticos para a infância, instrumentos que vão na contramão de um processo de objetificação das liberdades desses sujeitos.

Há, portanto, ganhos de racionalidade normativa para os sistemas de responsabilização dos Estados que aderiram à Convenção, embora se reconheça que, na prática, esses ganhos decorrem de um complexo processo de resistência ao abuso nas formas de intervenção do Estado, como também, no permanente processo de luta pelo reconhecimento de que crianças e adolescentes são sujeitos de direitos (ALBUQUERQUE, 2015).

Desde outro ponto de vista, a partir da compreensão de que a intervenção dos Estados sobre as liberdades de crianças é atividade vinculada e, portanto, sujeita à limitação e ao controle, é que se pode radicar, no âmbito dos Estados-parte da Convenção, os seus respectivos modelos de responsabilização em um paradigma democrático de intervenção, entendendo-se aí que a relação entre democracia e resposta estatal se estabelece toda vez que se reconhece como pressuposto a existência de "regras do jogo" para o exercício deste poder e a impossibilidade de essas regras subverterem a irrenunciável condição de titularidade de direitos, por parte daqueles que, eventualmente, serão submetidos a essa forma de intervenção.

A responsabilização de adolescentes no Brasil: entre permanências e rupturas

No Brasil, o advento da Convenção e ECA trouxe importantes diretrizes, conforme exposto. Esses documentos contribuíram para tencionar com o modelo menorista até 
então vigente buscando rupturas. O menorismo, no Brasil, tem como um dos seus marcos legais a aprovação do Código de Menores, o Decreto $n^{\circ} .17 .943$ de 12 de outubro de 1927.

Neri e Oliveira (2010: 2) apontam que no menorismo há um foco nas crianças e nos adolescentes em situação de privação da convivência familiar ou que cometeram delitos, porém, não com eixo na proteção, mas, de forma mais significativa, na punição. Queiroz (2013) complementa o entendimento dos autores, aduzindo que "os destinatários dessas normas eram somente aqueles que estivessem em 'situação de perigo moral ou material' ou em 'situação irregular', termos estes definidos em lei e tratados como uma patologia social". Ou seja, nota-se, desde então, uma política higienista ${ }^{10}$ e contraditória, uma vez que, ao mesmo tempo em que se desejava proteger esta criança, almejava-se contê-la, sendo a noção de delinquência relacionada à pobreza infantil e com profundo viés racial. Necessário observar o que dispunha o Código em seu artigo 55, alínea b:

Art. 55. A autoridade, a quem incumbir a assistência e proteção aos menores, ordenará a apreensão daqueles de que houver noticia, ou the forem presentes, como abandonados os depositará em lugar conveniente, 0 providenciará sobre sua guarda, educação e vigilância, podendo, conforme, a idade, instrução, profissão, saúde, abandono ou perversão do menor e a situação social, moral e econômica dos pais ou tutor, ou pessoa encarregada de sua guarda, adotar uma das seguintes decisões. (...)

b) entregá-lo a pessoa idônea, ou interná-lo em hospital, asilo, instituto de educação, oficina escola da preservação ou de reforma (...) (BRASIL, 1927).

A política higienista' acima referida pode ser facilmente exemplificada no dispositivo acima, uma vez que uma opção para o "menor abandonado" era a internação. Rizzini (2000: 13) aponta que a legislação da época:

Respondia aos temores abertamente propagados em relação ao aumento da criminalidade infantil. E, ao mesmo tempo, atendia à dupla demanda de proteção à criança e à sociedade, à medida em que buscava deter aqueles que ameaçavam a ordem.

\footnotetext{
${ }^{10}$ Oliveira (2012, p. 101-102) salienta que a política higienista é entendida como a representação "(d)o alcance ideal de nação civilizada, de pretenso progresso do tratamento da questão da infância no Brasil. A aliança entre médicos e juristas, na primeira metade do século XX era direcionada para a construção de um saber e um sujeito de conhecimento e controle, visando o melhor aparelhamento institucional, capaz de 'salvar' a infância brasileira, tornando a própria vida das crianças objeto de pensamento e ação de conjunto heterogêneo de especialistas". A abordagem sanitarista-higienista tinha como meta "aperfeiçoar" a população, por meio da expansão estatal na vida privada, a fim de "civilizá-los".
} 
Ainda que 0 artigo 10 do Código de Menores ${ }^{11}$ trouxesse como objetivos a assistência e proteção da criança, o que se percebeu foi uma estigmatização daquela que tinha origem pobre, em especial as crianças negras que descendiam de pessoas escravizadas. Neri e Oliveira (2010: 3) reforçam essa ideia ao citar que a criação do termo "menor" "passou a denominar uma categoria perigosa ou com possibilidade de oferecer perigo se não houvesse interferência institucional do Estado".

É possível perceber, então, que a política não era voltada a todas as crianças, em qualquer situação que estivesse. Estas eram vistas tão somente como um objeto de direitos e não sujeito destes. Havia uma nítida divisão entre a criança ou a adolescente negra e pobre e aquela branca com melhores condições, uma vez que, em momento algum no Código cita-se qual medida é aplicada ao "menor" advindo de famílias privilegiadas (o termo "menor" sequer era aplicado a eles) que comete infrações.

Cronologicamente, na década de 40 , atendendo à política no combate à criminalidade infanto-juvenil, Teixeira (2005: s.p) destaca a criação do Serviço de Atendimento dos Menores (SAM), cuja existência foi "extremamente conturbada, sobretudo quando passou a ser concebida como inadequada ao tratamento dos 'menores'”. Instituída pelo Decreto n'. 3.799 de 1941, esta política de atendimento ${ }^{12}$ tinha como objetivo, no dizer de Barbosa Davim et al (2009: 134):

(...) atender menores carentes e delinquentes, institucionalizá-los e estudálos. O SAM administrava orfanatos e escolas-modelo que funcionavam como reformatórios, desenvolvendo péssima reputação à vista do público e da imprensa, como sendo prisões, imperando torturas, drogas, violência, abuso sexual e corrupção administrativa.

Nota-se, então, que não havia uma política individualizada, sequer a configuração da socioeducação, mas tão somente um depósito social, entendimento que permeava inclusive o imaginário popular. Rizzini e Rizzini (2004: 34) dissertam que "o SAM acaba por se transformar em uma instituição para prisão de menores

\footnotetext{
${ }^{11}$ “Art. 10 0 menor, de um ou outro sexo, abandonado ou delinquente, que tiver menos de 18 anos de idade, será submetido pela autoridade competente às medidas de assistência e proteção contidas neste Código" (BRASIL, 1927).

${ }^{12} \mathrm{Em}$ 1944, o Decreto $\mathrm{n}^{\circ}$. 6.865, por conta dos problemas enfrentados pelo SAM, redefiniu das suas competências. Faleiros (1995: 69 apudPEREZ E PASSONE, 2010: 5) aponta quais mudanças ocorreram: "orientar e fiscalizar as entidades particulares; diagnosticar os casos em que caberiam internação e ajustamento social, por meio de exames médico-psicopedagógicos; encaminhar e abrigar os menores aos estabelecimentos, bem como, supervisionar e controlar as instituições particulares que recebiam subvenções do Estado".
} 
transviados em uma escola do crime". Ou seja, houve uma construção midiática e social para que assim se entendesse a Política do SAM. Continuam as autoras: "A passagem pelo SAM tornava o rapaz temido e indelevelmente marcado".

Posteriormente, em 1964, no âmbito nacional, Perez e Passone (2010: 13) destacam o estabelecimento da Política Nacional de Bem-Estar do Menor (PNBEM), que, por sua vez, introduziu a rede nacional da Fundação do Bem-Estar do Menor (FUNABEM), cujos objetivos foram elencados por Barbosa Davim et al. (2009: 4):

Elaborar e promover políticas de bem-estar para a criança e o adolescente, distribuir recursos e financiar as executoras de programas em nível estadual - as Fundações Estaduais do Bem-Estar do Menor (FEBEM). Criada pelo Estado, a FEBEM objetivava abrigar crianças e adolescentes em situação de abandono, que deveria revolucionar a atenção, promover abordagens socioeducativas e a desinstitucionalização.

A FUNABEM, no entendimento de Rizzini e Rizzini (2004), tinha como objetivo ser uma política "Anti-SAM", com diretrizes contrárias àquela instituída no governo ditatorial. Objetivava, ademais, a partir de uma autonomia financeira e administrativa, afastar o perfil de "depósito de menores", um verdadeiro internato de jovens advindo de classes economicamente desfavorecidas.

O que se verificou na prática foi que "o recolhimento de crianças das ruas foi intensificado, conforme atesta o Boletim Informativo da MUDES (no 8, nov. 1972)" (RIZZINI; RIZZINI, 2004: 37). Notou-se, então, que a aludida intensificação tinha como objetivo demonstrar a dimensão do "problema" que eram os "menores", frente à segurança pública.

Em 1979, adveio no sistema legislativo brasileiro o segundo Código de Menores, que reafirmou a política menorista sob o manto do conceito de "situação irregular"13. Rizzini (2010: 70) discorre que "a Lei n 6.697/79, aprovada em 10 de outubro de 1979, refletia a fidelidade dos Juízes de Menores à velha lei de Mello Matos, adaptando-a aos novos tempos". Ou seja, houve apenas uma reconfiguração do antigo Código,

\footnotetext{
13 “Art 2ㅇ Para os efeitos deste Código, considera-se em situação irregular o menor: I - privado de condições essenciais à sua subsistência, saúde e instrução obrigatória, ainda que eventualmente, em razão de: a) falta, ação ou omissão dos pais ou responsável; b) manifesta impossibilidade dos pais ou responsável para provêlas; II - vítima de maus tratos ou castigos imoderados impostos pelos pais ou responsável; III - em perigo moral, devido a: a) encontrar-se, de modo habitual, em ambiente contrário aos bons costumes; b) exploração em atividade contrária aos bons costumes; IV - privado de representação ou assistência legal, pela falta eventual dos pais ou responsável; $V$ - Com desvio de conduta, em virtude de grave inadaptação familiar ou comunitária; VI - autor de infração penal” (BRASIL, 1979).
} 
reforçando inclusive a ideia de que as crianças e adolescentes são sujeitos incapazes, desconsiderando, além dos avanços em âmbito internacional, o estado de pessoas em condição peculiar de desenvolvimento, sendo meros objetos de direito (QUEIROZ, 2013).

As crianças negras e pobres continuaram sendo criminalizadas e contidas, sob um discurso moralizante que desconsiderava o papel do Estado na produção de desigualdades e atribuía aos pais e mães a responsabilidade pelo cuidado das crianças. Estas eram internadas nos mesmos estabelecimentos independentes de serem oriundas de famílias dificuldades de sustento ou terem cometido infrações penais. É o que aponta Queiroz (2013: 51):

Neste tempo, de vigência do Código de Menores, a grande maioria da população infanto-juvenil recolhida às entidades de internação do sistema FEBEM no Brasil, na ordem de $80 \%$, era formada por crianças e adolescente, "menores", que não eram autores de fatos definidos como crime na legislação penal brasileira. Estava consagrado um sistema de controle da pobreza, que Emílio Garcia Mendez define como sociopenal, na medida em que se aplicavam sanções de privação de liberdade a situações não tipificadas como delito, subtraindo-se garantias processuais. Prendiam a vítima. Esta também era a ordem que imperava nos Juizados de Menores.

Silva (2000: 11) aduz que a Constituição Federal de 1988 - CF, pela primeira vez na história política do país, trouxe a questão da criança como absoluta prioridade, sendo a sua proteção dever da família, da sociedade e do Estado (art. 227, CF). É o que também entende Martins (2004: 66) ao afirmar que a nova ordem constitucional "atribuiu à criança e ao adolescente a condição de sujeitos de direitos, declarando-lhes proteção especial e prioridade imediata e absoluta", consagrando a chamada Doutrina da Proteção Integral.

Para Oliveira (2012), a qualificação de sujeitos de direitos às crianças e aos adolescentes possibilitou a estruturação de concepção (proteção integral), gestão (participativa e descentralizada) e método (não assistencialista e, quanto aos atos infracionais, de caráter socioeducativo) com a objetivação das relações.

A Constituição de 1988, em seu artigo 228 , também contribui nesse processo ao fixar a imputabilidade penal aos dezoito anos de idade, reiterando o que já dispunha o Código Penal de $1940^{14}$, designando um sistema especial de responsabilização, em

\footnotetext{
${ }^{14}$ Decreto-lei $n^{\circ}$. 2.848, de 7 de dezembro de 1940.
} 
consonância com os diversos documentos internacionais. Antes do Código Penal, poucos documentos preocuparam-se em fixar uma idade mínima de responsabilização, sendo em regra aplicadas as normas penais a partir de parca idade.

De acordo com as Ordenações Filipinas (1603), no Brasil Colônia, os menores de 7 anos eram absolutamente incapazes. No Código Criminal de 1830, no Brasil República, a inimputabilidade penal foi fixada entre 07 e 14 anos, sendo responsabilizados a medida da avaliação do magistrado sobre seu "discernimento". No Código Penal dos Estados Unidos do Brasil de 1890, a inimputabilidade plena foi ampliada aos 09 anos e a inimputabilidade relativa de 09 a 14.A Lei 4242/1921 elimina o critério de discernimento, considerando a pessoa menor de 14 completamente isenta de responsabilidade o que seria ratificado no primeiro Código de Menores.

Percebe-se assim o avanço da determinação constitucional, estabelecendo um critério etário de proteção do alcance do sistema penal independente de avaliações arbitrárias. OECA, para tanto, estabeleceu as medidas de responsabilização e delineou o ato infracional, as condutas descritas como crime e contravenção nos termos da lei penal. Importante observar que as medidas socioeducativas, previstas no artigo $112^{15}$, somente podem ser aplicadas aos adolescentes, definindo-se três anos como tempo máximo de internação e liberdade compulsória aos 21 anos (art. 121). No caso das crianças podem ser aplicadas as medidas de proteção previstas no artigo $101^{16}$.

No Brasil, foi também essencial para a execução das medidas socioeducativas a criação do Sistema Nacional de Atendimento Socioeducativo - SINASE, em 2006, pelo Conselho Nacional dos Direitos da Criança e do Adolescente - CONANDA, por meio da Resolução №. 119, que estabeleceu importantes diretrizes para aplicação dessas medidas. Em 2012, o Congresso aprovou a Lei $n^{\circ}$. 12.594, que instituiu o SINASE em

\footnotetext{
15“Art. 112. Verificada a prática de ato infracional, a autoridade competente poderá aplicar ao adolescente as seguintes medidas: I - advertência; II - obrigação de reparar o dano; III - prestação de serviços à comunidade; IV - liberdade assistida; V - inserção em regime de semiliberdade; VI - internação em estabelecimento educacional; VII - qualquer uma das previstas no art. 101, I a VI" (BRASIL, 1990b).

${ }^{16}$ “Art. 101. Verificada qualquer das hipóteses previstas no art. 98, a autoridade competente poderá determinar, dentre outras, as seguintes medidas: I - encaminhamento aos pais ou responsável, mediante termo de responsabilidade; II - orientação, apoio e acompanhamento temporários; III - matrícula e frequência obrigatórias em estabelecimento oficial de ensino fundamental; IV - inclusão em programa comunitário ou oficial de auxílio à família, à criança e ao adolescente; IV - inclusão em serviços e programas oficiais ou comunitários de proteção, apoio e promoção da família, da criança e do adolescente; $V$ requisição de tratamento médico, psicológico ou psiquiátrico, em regime hospitalar ou ambulatorial; VI inclusão em programa oficial ou comunitário de auxílio, orientação e tratamento a alcoólatras e toxicômanos; VII - abrigo em entidade; VII - acolhimento institucional; VIII - colocação em família substituta; VIII - inclusão em programa de acolhimento familiar; IX - colocação em família substituta" (BRASIL, 1990b).
} 
termos legais regulamentando a execução das medidas socioeducativas destinadas a adolescentes que pratiquem ato infracional. Em 2013, foi criado, pela Secretaria de Direitos Humanos da Presidência da República, o Plano Nacional de Atendimento Socioeducativo, com metas e eixos operativos para o SINASE.

Segundo o Comitê sobre Direitos da Criança, o Brasil cunhou, com todos esses instrumentos, um dos melhores sistemas de responsabilização juvenil do mundo sendo necessária, contudo, uma maior atenção para a implantação do SINASE $^{17}$.Embora tenha havido grande avanço legal, a execução da política ainda apresenta enormes desafios para garantir o cumprimento dos direitos estabelecidos.

A responsabilização de adolescentes, no Brasil, sobretudo após a entrada em vigor dos instrumentos acima mencionados, sofreu significativo impacto no que diz respeito à (re)construção de um modelo democrático de intervenção. Segundo Karyna Batista Sposato (2006), todavia, o sistema criado pelo ECA a partir da noção de imputabilidade omite o viés penal, o que beneficiou a seletividade do sistema que sempre criminalizou determinados adolescentes negros e pobres.

É possível identificar permanências menoristas na trajetória de consolidação desse sistema. Se tomada como uma das principais características da intervenção estatal menorista, a excessiva discricionariedade do juiz ainda encontra inúmeras formas de atualização, no interior do sistema forjado a partir da Constituição de 1988, do ECA e demais leis estruturantes do sistema.

A internação de adolescentes pela suposta prática de ato infracional é exemplo privilegiado dessa sintomática nódoa menorista. Apesar de suas hipóteses de cabimento encontrarem previsão taxativa no ECA, não raro os Tribunais autorizam a aplicação da medida fora das hipóteses legais, para alcançar situações que a própria legislação determina a priorização de medidas outras diversas da grave restrição de liberdade (ALBUQUERQUE, 2015).

Não bastasse, o discurso que excede a punição, nesse contexto, apropria-se de um arsenal semântico de proteção ao adolescente, de seu melhor interesse e de sua condição peculiar, indo, pois, na contramão da história de consolidação desses

17 AÇÃO EDUCATIVA. "Comitê sobre os Direitos da Criança da ONU considera alertas da sociedade civil brasileira durante 70을. Sessão". Disponível em: <http://acaoeducativa.org.br/blog/2015/09/25/comitesobre-os-direitos-da-crianca-da-onu-considera-alertas-da-sociedade-civil-brasileira-durante-70o-sessao/>.

Acesso em: 23 nov. 2018. 
princípios, que se dirigem exatamente à limitação da intervenção do Estado, na exata medida de sua justificação enquanto corresponsável pela efetividade de direitos.

Disso decorre que o menorismo, embora afastado do ponto normativo, é prática que atravessa culturalmente o sistema de garantias, ainda hoje. Não raro, é possível encontrar decisões do Superior Tribunal de Justiça (STJ), em matéria infracional, que ainda se referem ao adolescente como "menor", ou ainda, à sentença judicial como “sentença menorista" ${ }^{18}$, reforçando o lugar desses sujeitos a partir de uma categoria objetificadora absolutamente dissonante do que se estabeleceu, historicamente, em termos de proteção jurídica da adolescência.

Outras demandas por reconhecimento ainda tencionam a efetivação de um sistema de garantias. A Lei $\mathrm{n}^{\circ}$. 12.594/2012 é um significativo exemplo, no que diz respeito ao estabelecimento de fruição de direitos, por adolescentes em contexto de cumprimento de medidas socioeducativas. Veja-se o caso dos direitos sexuais, pauta jurídica de proteção ainda atravessada por desafios, questionamentos e tensões, sendo paulatinamente incorporada nas estratégias de atuação das entidades de atendimento socioeducativo e que dizem respeito, em síntese, ao compromisso radical com o pressuposto de cidadania e de titularidade de direitos, por parte de adolescentes, mesmo os que se encontram sob a intervenção enfática do Estado.

Esses elementos permitem considerar que, historicamente (e a Convenção é peça chave nesse processo), a condição de sujeitos de direitos é lugar que se deve conquistar diariamente, na dinâmica social. Os direitos enunciados na Convenção não traduzem dádivas estatais, mas elementos de permanente tensão na relação que se estabelece entre a cidadania e a atuação do Estado, mais ainda levando-se em consideração as peculiaridades dos sujeitos de direitos envolvidos nesse processo.

A intervenção do Estado sobre a liberdade, pelo risco sempre presente de ultrapassar esses limites em direção ao abuso é contexto que necessita, diariamente, da autocrítica e do controle a partir de parâmetros normativos seguros, como é o caso da Convenção, sob pena de se direcionar a atuação estatal ao retrocesso menorista; o que, aliás, como ainda se verá no tópico seguinte, é fator de risco cada vez mais presente,

\footnotetext{
${ }^{18}$ HC 263.401. SP. Quinta Turma, Rel. Min. Laurita Vaz, DJe 17/04/2013.
} 
nos últimos anos, desde o fortalecimento de discursos neomenoristas ${ }^{19}$, que atualizam a ideia de máxima intervenção e de enfraquecimento de direitos, no campo da infância.

\section{Demandas punitivista a socioeducação}

Nas últimas décadas tem crescido o número de prisões e, ao mesmo tempo, discursos punitivistas. Estes discursos, que afirmam a necessidade de reforço do sistema punitivo, introjetam-se nos agentes do sistema penal e na população como um todo com forte efeito multiplicador (ZAFFARONI et al., 2011). Segundo Carvalho (2010), a chamada "guerra às drogas" tornou-se o eixo central nesta demanda punitiva, sendo absorvida pelos países latino-americanos renovando seu discurso jurídico-político-belicista.

Budó, Silva e Dias (2018), ao analisar editorias de jornais, concluem que a representação social do adolescente autor de ato infracional reproduz estereótipos que o identificam como um inimigo da sociedade, não por acaso aparecendo a proposta de aumento da punição por meio do encarceramento precoce como a solução para o problema da violência.

Os discursos punitivistas têm se expandido nas mais diversas áreas e impactado diretamente a aplicação das medidas socioeducativas com: a) o fortalecimento de discursos de redução da maioridade penal; b) o crescimento do número de adolescentes privados de liberdade, com a aplicação da internação como resposta principal ao cometimento do ato infracional; c) a resistência às medidas alternativas ao cárcere; e d) o desrespeito às garantias constitucionais, como o acesso à justiça e o devido processo legal.

Sobre a redução da maioridade penal, estão em tramitação vários projetos legislativos com propostas de emenda à constituição ${ }^{20}$ para redução da maioridade penal e propostas de alteração no ECA para ampliação do tempo de internação ${ }^{21}$ o que

\footnotetext{
${ }^{19}$ Para Mendez (2011), os discursos neomenoristas representam uma fase atual de involução autoritária que se dissemina na América Latina.

${ }^{20}$ Uma das propostas é o Projeto de Emenda Constitucional no. 171/1993, reduzindo a maioridade penal de 18 para 16 anos.

${ }^{21} \mathrm{Um}$ dos Projetos de Lei é do Senado, de no. 333/2015, que aumenta a pena máxima de internação de 3 para 10 anos.
} 
pode implicar graves retrocessos, sendo esta uma pauta prioritária do presidente eleito Jair Bolsonaro ${ }^{22}$.

Segundo Cappi (2014), ao analisar projetos de redução da maioridade penal, verifica-se um discurso de que esses jovens são elementos de uma classe perigosa, fortemente responsáveis pelo aumento da insegurança, contra a qual é essencial reforçar a resposta punitiva, numa perspectiva explicitamente retributiva ou dissuasiva. A noção de "responsabilidade" é puramente reduzida a dureza da sentença.

Percebe-se assim como esses discursos vão na contramão do discurso de proteção integral que movimentou os avanços legais e da perspectiva garantista de ascensão do direito penal moderno.

O Comitê sobre os Direitos da Criança manifestou preocupação com as propostas de redução da maioridade penal e de aumento da internação, que podem ser tão danosas quanto as primeiras, sugerindo que o SINASE seja efetivamente implantado ${ }^{23}$.

Ao contrário dos discursos que pregam a necessidade de ampliar os mecanismos de punição diante de uma suposta "impunidade" com o sistema de responsabilização trazido pelo ECA, o que se observa e o crescimento significativo dos adolescentes em privação de liberdade ${ }^{24}$.

Conforme o Levantamento anual do SINASE (BRASIL, 2018),47\% (12.960) do total de atos infracionais em 2016 foram classificados como análogo a roubo (acrescido de $1 \%$ de tentativa de roubo), e $22 \%$ (6.254) foram registrados como análogo ao tráfico de drogas. $O$ ato infracional análogo ao homicídio foi registrado em 10\% (2.730) do total de atos praticados, acrescido de 3\% de tentativa de homicídio. Percebe-se, nesses dados, que a maioria dos atos infracionais não está relaciona à violência contra a pessoa. Além disso, pode-se observar o impacto da chamada "guerra às drogas",

\footnotetext{
22 KERVALT, Marcelo. "Propostas de redução da idade penal devem ser discutidas no Congresso em 2019". Disponível em: <https://gauchazh.clicrbs.com.br/seguranca/noticia/2018/11/propostas-de-reducao-daidade-penal-devem-ser-discutidas-no-congresso-em-2019-cjok7x85z0ecx01rx7cp2j3ru.html>. Acesso em 22 nov. 2018.

${ }^{23}$ AÇÃO EDUCATIVA. "Comitê sobre os Direitos da Criança da ONU considera alertas da sociedade civil brasileira durante 70o Sessão". Disponível em: <http://acaoeducativa.org.br/blog/2015/09/25/comitesobre-os-direitos-da-crianca-da-onu-considera-alertas-da-sociedade-civil-brasileira-durante-70o-sessao/>. Acesso em: 23 nov. 2018.

${ }^{24}$ REDE BRASIL ATUAL. "Em seis anos, número de jovens cumprindo medida privativa de liberdade aumenta em 58,6\%". Disponível em: <https://www.redebrasilatual.com.br/cidadania/2018/02/em-seis-anos-numerode-jovens-cumprindo-pena-aumenta-em-58>.Acesso em 22 nov. 2018.
} 
moldada em modelos proibicionistas, que afetam jovens negros e pobres no Brasil (SOUZA et al., 2017).

Além do grande número de adolescentes privados de liberdade, observa-se que o tratamento dispensado aos adolescentes, no Brasil, se assemelha, e muito, às prisões para adultos. De acordo com o Conselho Nacional do Ministério Público - CNMP (2015), na execução das medidas socioeducativas de internação, há várias violações aos direitos humanos dos adolescentes, desde as deficitárias estruturas físicas, à problemas referentes à escolarização, higiene e saúde. No Levantamento anual do SINASE (BRASIL, 2016), no ano de 2016, foram a óbito 49adolescentes vinculados às unidades de atendimento socioeducativo em situações de privações de direitos e outras que caracterizariam a prática da tortura.

Outro aspecto a ser considerado no mar de violações aos direitos dos adolescentes em conflito com a lei diz respeito ao não acesso à justiça e ao devido processo legal, previsto na Constituição Federal (art. 5ㅇ), no ECA (art. 110) e em instrumentos internacionais como a Convenção sobre os Direitos da Criança (art. 40). Segundo o documento base da XI Conferência Nacional dos Direitos da Criança e do Adolescente, redigido pelo CONANDA (2018, p.20), vários são os fatores que impedem a garantia desse direito, tais como:

Entre eles podemos citar o fato de que crianças e adolescentes nem sempre são ouvidos nesses espaços; o desconhecimento dos seus direitos de forma clara; a não informação do devido processo legal a que estão sendo submetidos; a ausência de advogados ou de defensores públicos para a defesa qualificada, dentre outras questões; a re-vitimização a que são submetidos crianças e adolescentes cujos direitos são violados e passam por vários órgãos de atendimento; procedimentos inadequados que promovem a exposição da vítima, constituindo-se em flagrante violação de outros direitos.

Boa parte desses adolescentes ainda sofre com a falta de acesso à justiça, de informações básicas sobre seus direitos que poderiam ser obtidas, por exemplo, por meio da conversa com advogados/as e com juízes/juízas, mas que se tornam escassas 
diante dos limites da defensoria pública com grande falta de defensores na infância ${ }^{25} \mathrm{e}$ de varas especializadas ${ }^{26}$ (CNJ, 2015).

Mesmo deparando-se com esse quadro, ainda há uma baixa aplicação de medidas alternativas à privação da liberdade. Segundo pesquisa feita pelas Nações Unidas $(2018)^{27}$, a semiliberdade é subutilizada no Brasil. O Comitê sobre os Direitos da Criança, em relatório emitido em 2015, externou preocupação com a execução das medidas alternativas à internação não serem aplicadas de forma eficaz, resultando em um número elevado de adolescentes, especialmente negros, cumprindo estas medidas, e, por isso, emitiu uma série de recomendações. O Comitê também encaminhou sua preocupação ao Grupo de Trabalho sobre Detenção Arbitrária referente aos vários casos de adolescentes detidos por delitos leves ${ }^{28}$.

Segundo Tangerino e Ferraz (2016), o discurso que operacionalizou a criação das medidas socioeducativas foi a de um viés pedagógico e retributivo que hoje não há mais como sustentar diante da dura realidade. Segundo os autores, deve-se visualizar a medida pelo seu viés punitivo, que a aproxima da natureza das penas. Desnudar esses discursos contribui para reforçar a importância do respeito a um sistema de garantias.

\section{Considerações finais}

Conforme observado ao longo do artigo, a Convenção da Criança representa a expressão de uma profunda transformação cultural, normativa e social no trato para com a criança, rompendo com a produção teórica anteriormente vigente, que não considerava a infância como construção social, tampouco tratava a criança como sujeito de direito.

${ }^{25}$ AGÊNCIA LUPA. "Quando a Justiça não alcança: faltam quase 10 mil defensores públicos no Brasil". Disponível em: <https://piaui.folha.uol.com.br/lupa/2017/04/19/falta-defensoria-publica-brasil/>. Acesso em: 20 nov. 2018

26 G1. "Só $12 \%$ das Varas da Infância no país são exclusivas, segundo CNJ". Disponível em: <http://g1.globo.com/politica/noticia/2014/05/so-12-das-varas-da-infancia-no-pais-sao-exclusivassegundo-cnj.html>. Acesso em: 20 nov. 2018.

${ }^{27}$ ONU BRASIL. "Estudo afirma que semiliberdade é subutilizada no sistema socioeducativo brasileiro". Disponível em: <https://nacoesunidas.org/estudo-afirma-que-semiliberdade-e-subutilizada-no-sistemasocioeducativo-brasileiro/>. Acesso em: 20 nov. 2018.

${ }^{28}$ AÇÃO EDUCATIVA. "Comitê sobre os Direitos da Criança da ONU considera alertas da sociedade civil brasileira durante 70을. Sessão". Disponível em: <http://acaoeducativa.org.br/blog/2015/09/25/comitesobre-os-direitos-da-crianca-da-onu-considera-alertas-da-sociedade-civil-brasileira-durante-70o-sessao/>. Acesso em: 23 nov. 2018. 
Contudo, o aludido documento não está isento de ambiguidades e contradições, em especial no decurso histórico de sua implementação.

No Brasil, o impacto da Convenção trouxe inúmeros avanços, em especial em termos normativos, todavia, é urgente e necessária a avaliação do atual sistema nacional socioeducativo. Nos 30 anos da Convenção deve-se retomar a importância de um sistema de direitos e garantias para esses adolescentes para que sob o discurso da "socioeducação" não continue permitindo violências e arbítrios.

O sistema socioeducativo vigente no Brasil expressa permanências menoristas que resistem em assegurar direitos e garantias aos adolescentes, seja por meio de políticas etnocêntricas, que qualificam a criança não privilegiada como um problema a ser tratado - visto que é entendida como um potencial perigo, ou ainda de construções sociais estigmatizantes, que atingem o indivíduo desde a infância e que são reproduzidos nas instituições estatais, responsáveis por internalizar a compressão de que são sujeitos sem valor, já que advindos de famílias "desestruturadas".

Aliado a isto, o impacto dos discursos punitivistas, pautados em um controle do delito, tem contribuído para questionar o funcionamento de um sistema particular de responsabilização, notadamente violento e seletivo, que busca manter o socioeducando dentro de parâmetros controláveis, o que não coaduna de modo algum com o prelecionado na Convenção.

Compreende-se que não se deve presumir que as normas, tão somente, sejam as responsáveis por transformar a abordagem factual da infância e adolescência em âmbito infracional. O debate crítico, seja na esfera política, acadêmica ou social, deve ser ordenado no sentido de romper com todo o sistema de desigualdade social vigente em âmbito mundial - impraticável nos dias atuais, na constância do neoliberalismo. Enquanto isso, o que resta é encontrar e resgatar as ferramentas que se alinham com o combate às dissimetrias excessivas entre as infâncias.

É fundamental assim que se resgate os avanços da Convenção e que sejam fortalecidos os mecanismos de monitoramento, tais como os Conselhos de Direitos, e de denúncias, principalmente através da ação de um fortalecido e integrado Sistema de Garantia dos Direitos que também precisa ser capacitado para lidar com essas demandas. 


\section{Referências Bibliográficas}

ABOIM, Josilene Barbosa. O capital humano dos adolescentes infratores: uma análise a partir das falas da juventude internada em Ananindeua - Pa. Dissertação (mestrado). Programa de Pós-Graduação em Direito da Universidade Federal do Pará. Belém, 2018.

ALBUQUERQUE, Fernando da Silva. Entre a crise de interpretação e a crítica: a hermenêutica como condição de possibilidade para o controle da internação - (des) medida. Dissertação (mestrado). Programa de Pós-Graduação em Direito da Universidade Federal do Pará. Belém, 2015.

ANDRADE, Lucimary Bernabé Pedrosa de. "Educação infantil: discurso, legislação e práticas institucionais" [online] São Paulo: Editora UNESP; São Paulo: Cultura Acadêmica, 2010. Disponível em: <http://books.scielo.org/id/h8pyf/pdf/andrade-978857983085307.pdf>. Acesso em: 13 jun. 2018.

ARIÉS, P. História social da infância e da família. Rio de Janeiro: LCT, 1978.

BARBOSA DAVIM, Rejane Marie et al. "Adolescente/adolescência: revisão teórica sobre uma fase crítica da vida". Revista da Rede de Enfermagem do Nordeste, Fortaleza, v. 10, 2009, n. 2.

BRASIL. Decreto no 17.943-a de 12 de outubro de 1927.Consolida as leis de assistencia e protecção a menores. CLBR, Rio de Janeiro, RJ, 31 dez 1927. Disponível em: <http://www.planalto.gov.br/ccivil_03/decreto/1910-1929/D17943A.htm>. Acesso em: 19 nov. 2018.

BRASIL. Lei n. 6.697, de 10 de outubro de 1979. Institui o Código de Menores. Diário Oficial da República Federativa do Brasil, Brasília, DF, 11 out. 1979. Disponível em: <http://www.planalto.gov.br/ccivil_03/LEIS/1970-1979/L6697.htm>. Acesso em: 19 nov. 2018.

BRASIL. Constituição da República. 1988. Diário Oficial da República Federativa do Brasil, Brasília, DF, 5 out. 1988.Disponível em: <http://www.planalto.gov.br/ccivil_03/Constituicao/Constituicao.htm>. Acesso em: 19 nov. 2018.

BRASIL. Decreto no 99.710, de 21 de novembro de 1990. Promulga a Convenção sobre os Direitos da Criança. Diário Oficial da República Federativa do Brasil, Brasília, DF, 22 nov. 1990a. Disponível em: <http://www.planalto.gov.br/ccivil_03/decreto/19901994/d99710.htm>. Acesso em: 19 nov. 2018. 
Lei no 8.069, de 13 de julho de 1990. Dispõe sobre o Estatuto da Criança e do Adolescente e dá outras providências. Diário Oficial da República Federativa do Brasil, Brasília, DF, 16 jul. 1990b. Disponível em: <http://www.planalto.gov.br/ccivil_03/LEIS/L8069.htm>. Acesso em: 19 nov. 2018. BRASIL. Plano Nacional de Atendimento Socioeducativo: Diretrizes e eixos operativos para o SINASE. Brasília: Secretaria de Direitos Humanos da Presidência da República, 2013. $39 \mathrm{p}$.

BRASIL. Lei no 12.594, de 18 de janeiro de 2012. Institui o Sistema Nacional de Atendimento Socioeducativo (Sinase), regulamenta a execução das medidas socioeducativas destinadas a adolescente que pratique ato infracional. Diário Oficial da República Federativa do Brasil, Brasília, DF, 19 jan. 2012. Disponível em: <http://www.planalto.gov.br/ccivil_03/_Ato2011-2014/2012/Lei/L12594.htm>. Acesso em: 19 nov. 2018.

BRASIL. Levantamento anual do SINASE. Brasília: Ministério dos Direitos Humanos, 2018. Disponível em: <http://www.mdh.gov.br/todas-asnoticias/2018/marco/Levantamento_2016Final.pdf>. Acesso em: 19 nov. 2018.

BUDÓ, Marília; DIAS, Felipe V.; SILVA, Patrícia. "A redução da maioridade penal: uma análise dos editoriais do jornal O Globo". Revista da Faculdade de Direito UFPR, Parána, v. 23 , n. 2018 , p. $115-143$.

CAPPI, Ricardo. "Pensando as respostas estatais às condutas criminalizadas: um estudo empírico dos debates parlamentares sobre a redução da maioridade penal (1993 2010)". Revista de Estudos Empíricos em Direito, vol. 1, 2014, n. 1.

CARVALHO, Salo de. O papel dos atores do sistema penal na era do punitivismo. Rio de Janeiro: Lúmen Juris, 2010.

CNJ. "Dos espaços aos direitos: a realidade da ressocialização na aplicação das medidas socioeducativas de internação das adolescentes do sexo feminino em conflito com a lei

nas cinco regiões". Disponível em: <http://www.cnj.jus.br/files/conteudo/destaques//arquivo/2015/05/0a489b951db2299 7453d6335e9d88c14.pdf>. Acesso em 20 nov. 2018.

CNMP. "Um olhar mais atento nas unidades de internação e semiliberdade para adolescentes". Disponível em: <http://www.cnmp.mp.br/portal/images/stories/Destaques/Publicacoes/Um_Olhar_ma is_Atento_02.07_WEB-completo-ok-1_1.pdf>. Acesso em: 19 nov. 2018. 
CONANDA. "Documento base da XI Conferência Nacional dos Direitos da Criança e do Adolescente". Disponível em: <http://www.direitosdacrianca.gov.br/copy_of_TEXTOBASEFINAL.pdf>. Acesso em: 19 nov. 2018.

CONANDA. "Sistema Nacional De Atendimento Socioeducativo - SINASE. Brasília-DF: CONANDA, 2006". Disponível em: <http://www.conselhodacrianca.al.gov.br/sala-deimprensa/publicacoes/sinase.pdf>. Acesso em: 19 nov. 2018.

MACIEL, Kátia Regina Ferreira Lobo Andrade. Curso de Direito da Criança e do Adolescente: aspectos teóricos e práticos. 4. ed. Rio de Janeiro: Lúmen Júris, 2010.

MENDEZ, Emílio Garcia. "Das relaciones publicas al neomenorismo: 20 años de Convención Internacional de los derechos del niño em America Latina (1989-2009)". In: Revista Internacional de História Política e Cultura Jurídica. vol. 3, no.1, janeiro-abril 2011, p. 117- 141, Rio de Janeiro.

NERI, Cristiano; OLIVEIRA, Luiz Carlos de. A doutrina da situação irregular e a doutrina da proteção integral: infância e adolescência sob controle e proteção do Estado. In: Simpósio Nacional de Educação, 21, 2010, Paraná. Anais... Paraná: Unioeste, 2010. p. 111.

OLIVEIRA, Assis da Costa. Direitos Humanos dos Indígenas Crianças: perspectivas para a construção da Doutrina da Proteção Plural. Dissertação(mestrado). Programa de PósGraduação em Direito da Universidade Federal do Pará. Belém, 2012.

ONU. "Regras Mínimas das Nações Unidas para Administração da Justiça Juvenil Regras de Beijing. Resolução 40/33 das Nações Unidades de 29 de novembro de 1985". Disponível em: <http://www2.camara.leg.br/atividade-legislativa/comissoes/comissoespermanentes/cdhm/comite-brasileiro-de-direitos-humanos-e-politicaexterna/RegrMinNacUniAdmJustInfJuv.html>. Acesso em: 19 nov. 2018.

ONU. "Princípios das Nações Unidas para a Prevenção da Delinquência Juvenil Diretrizes de Riad. Resolução 45/112 das Nações Unidades de 14 de dezembro de 1990". Disponível em: <http://www2.camara.leg.br/atividade-legislativa/comissoes/comissoespermanentes/cdhm/comite-brasileiro-de-direitos-humanos-e-politicaexterna/PrincNacUniPrevDeliqJuv.html>. Acesso em: 19 nov. 2018.

ONU. "Regras Mínimas das Nações Unidas para Proteção dos Jovens Privados de Liberdade - Regras de Havana. Resolução 45/113, de 14 de dezembro de 1990". Disponível

em: 
<http://gddc.ministeriopublico.pt/sites/default/files/regrasprotecaojovens.pdf $>$. Acesso em: 19 nov. 2018.

ONU. "Regras Mínimas das Nações Unidas para Medidas Não Privativas de Liberdade Regras de Tóquio. Resolução 45/110, de 14 de dezembro de 1990". Disponível em: <http://www.cnj.jus.br/files/conteudo/arquivo/2016/09/6ab7922434499259ffca072912 2b2d38.pdf>. Acesso em: 19 nov. 2018.

PEREZ, José Roberto Rus; PASSONE, Eric Ferdinando. "Políticas sociais de atendimento às crianças e aos adolescentes no Brasil". Cadernos de Pesquisa, São Paulo, v. 40, 2010, n. 140, p. 649-673.

QUEIROZ, Paulo Eduardo Cirino de. "Da Doutrina 'Menorista' à Proteção Integral: mudança de paradigma e desafios na sua implementação". Brasília: Conteúdo Jurídico. $2013 . \quad$ Disponível em: <http://www.conteudojuridico.com.br/?artigos\&ver=2.42716\&seo=1>. Acesso em: 02 ago. 2018.

RIZZINI, Irene. A criança e a lei no Brasil: revisitando a história (1822-2000). Brasília: Unicef, 2000.

RIZZINI, Irene; RIZZINI, Irma. A institucionalização de crianças no Brasil: percurso histórico e desafios do presente. Rio de Janeiro: Ed. PUC-Rio; São Paulo: Loyola, 2004.

ROSEMBERG, Fúlvia; MARIANO, Carmem Lúcia Sussel. "A convenção internacional sobre os direitos da criança: debates e tensões". Cadernos de Pesquisa, São Paulo, v. 40, n. 141, p. 693-728. Disponível em: $<$ http://www.scielo.br/scielo.php?script=sci_arttext\&pid=S0100-

$15742010000300003 \&$ Ing=en\&nrm=iso >. Acesso em: 4 dez. 2018.

SOUZA, Luanna Tomaz; LIMA JUNIOR, Grant Davis de Souza; SANTIAGO, Paulo Henrique Pinto. "Reflexos da 'guerra às drogas' nas medidas socioeducativas de internação. Disponível em: <http://emporiododireito.com.br/leitura/reflexos-da-guerra-as-drogasnas-medidas-socioeducativas-de-internacao>. Acesso em: 4 dez. 2018.

SPOSATO, Karyna Batista. O direito penal juvenil. São Paulo: Editora Revista dosTribunais, 2006.

TANGERINO, D. P. C.; FERRAZ, Hamilton Gonçalves. "Lineamentos de uma teoria agnóstica da medida socioeducativa". Revista de estudos criminais, Porto Alegre, v. 15, 2016, p. 67-98. 
TEIXEIRA, Maria de Lourdes Trassi. "A história da FEBEM-SP: uma perspectiva e um recorte. 2005". Disponível em: http://www.aasptjsp.org.br/artigo/app/app/app/index.php. Acesso em: 22 nov. 2018.

ZAFFARONI, E. Raúl; BATISTA, Nilo; ALAGIA, Alejandro; SLOKAR, Alejandro. Direito Penal Brasileiro: primeiro volume. 4. ed. Rio de Janeiro: Revan, 2011.

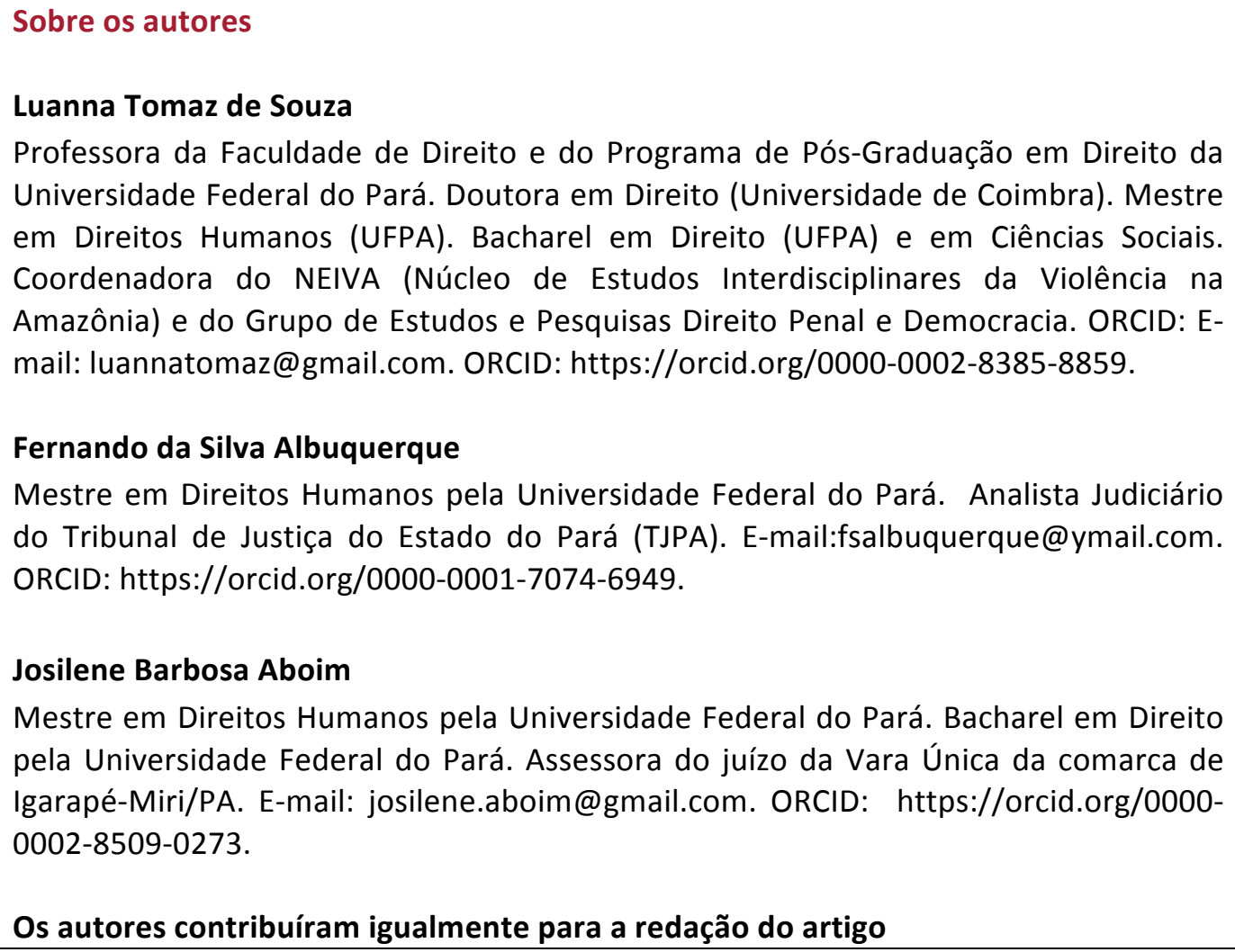
Universidade Federal do Pará. Doutora em Direito (Universidade de Coimbra). Mestre em Direitos Humanos (UFPA). Bacharel em Direito (UFPA) e em Ciências Sociais. Coordenadora do NEIVA (Núcleo de Estudos Interdisciplinares da Violência na Amazônia) e do Grupo de Estudos e Pesquisas Direito Penal e Democracia. ORCID: Email: luannatomaz@gmail.com. ORCID: https://orcid.org/0000-0002-8385-8859.

\section{Fernando da Silva Albuquerque}

Mestre em Direitos Humanos pela Universidade Federal do Pará. Analista Judiciário do Tribunal de Justiça do Estado do Pará (TJPA). E-mail:fsalbuquerque@ymail.com. ORCID: https://orcid.org/0000-0001-7074-6949.

\section{Josilene Barbosa Aboim}

Mestre em Direitos Humanos pela Universidade Federal do Pará. Bacharel em Direito pela Universidade Federal do Pará. Assessora do juízo da Vara Única da comarca de Igarapé-Miri/PA. E-mail: josilene.aboim@gmail.com. ORCID: https://orcid.org/00000002-8509-0273.

Os autores contribuíram igualmente para a redação do artigo 